\title{
New protocol for simplified reduction and fixation of subcondylar fractures of the mandible: a technical note
}

\author{
Saurabh Mohandas Kamat, Vikas Dhupar, Francis Akkara \\ Department of Oral and Maxillofacial Surgery, Goa Dental College and Hospital, Bambolim, India
}

\begin{abstract}
J Korean Assoc Oral Maxillofac Surg 2021;47:403-406)
The dilemma regarding the management of condylar fractures generally revolves around the surgical approach, implant design, and the surgeon's experience. Zide and Kent's guidelines streamlined the decision making process for condylar fractures. However, there exists no standardized protocol for reduction and fixation of condylar fractures. Here, we have described a detailed and stepwise protocol, common to any surgical approach, that would lead to predictable, reproducible, and repeatable results in every surgeon's hands.
\end{abstract}

Key words: Temporomandibular joint, Subcondylar fractures, Open reduction, Internal fixation

[paper submitted 2021. 7. 9 / revised 2021. 8. 28 / accepted 2021. 9. 6]

\section{Introduction}

The surgeon's dilemma regarding the management of condylar fractures has always revolved around the approach, timing, patient's age, implant design selection, and surgeon's experience. The criteria for open reduction of condylar fractures given by Zide and Kent ${ }^{1}$ marked one of the turning points in the decision-making and case selection process of condylar fractures. High condylar (intra-capsular/diacapitular) fractures pose a different surgical challenge, with the majority of surgeons preferring a closed reduction protocol for its management followed by physiotherapy ${ }^{2}$. The general consensus around the management of sub-condylar and low condylar fractures points towards open reduction and internal fixation. Even though the debate generally surrounds the incision, surgical approach, and implant design, we lack a detailed protocol-driven stepwise approach towards reduction and fixation of subcondylar fractures.

\section{Saurabh Mohandas Kamat}

Department of Oral and Maxillofacial Surgery, Goa Dental College and Hospital, Bambolim, Goa 403202, India

TEL: +91-8056895626

E-mail:kamat.saurabh@gmail.com

ORCID: https://orcid.org/0000-0002-8580-0298

(c) This is an open-access article distributed under the terms of the Creative Commons Attribution Non-Commercial License (http://creativecommons.org/ licenses/by-nc/4.0/), which permits unrestricted non-commercial use, distribution, and reproduction in any medium, provided the original work is properly cited.

Copyright (C) 2021 The Korean Association of Oral and Maxillofacial Surgeons.
This article aims to devise a detailed and standardized protocol, common to any surgical approach or implant design, that once followed, would lead to predictable, reproducible, and repeatable results in every surgeon's hands thereby eventually eliminating the uncertainty and difficulty in reduction and fixation of subcondylar fractures of the mandible.

\section{Technical Note}

A total of 34 condylar neck and condylar base (subcondylar) fractures, classified according to Loukota et al. ${ }^{3}$, were treated using our protocol under general anesthesia. In 21 cases, the proximal segments were antero-medially displaced and 13 cases had laterally displaced proximal segments. All the subcondylar fractures were approached using a retro-mandibular (antero-parotid transmassetric) approach.

As advocated by Orabona et al. ${ }^{4}$, fixation of concomitant fractures in the dentate part of the mandible were done first. Following which, our protocol was utilized for the reduction and fixation of the condylar neck and condylar base fractures.

\section{Step 1}

The mandible is antero-inferiorly distracted manually by placing a thumb over the ipsilateral molars intra-orally. 


\section{Step 2}

The posterior border of the proximal segment is identified and secured using a $16 \mathrm{~cm}$ Rochester-Pean curved hemostatic forceps (Fig. 1), with one beak over the cortical portion and the other beak placed into the medullary portion. Following which, the proximal segment is lateralized overriding the distal segment.(Fig. 2) This maneuver serves a dual purpose

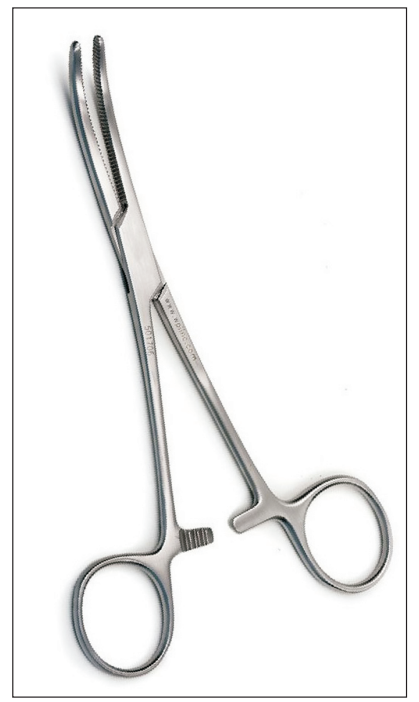

Fig. 1. Rochester-Pean curved hemostatic forceps $(16 \mathrm{~cm})$. Saurabh Mohandas Kamat et al: New protocol for simplified reduction and fixation of subcondylar fractures of the mandible: a technical note. J Korean Assoc Oral Maxillofac Surg 2021

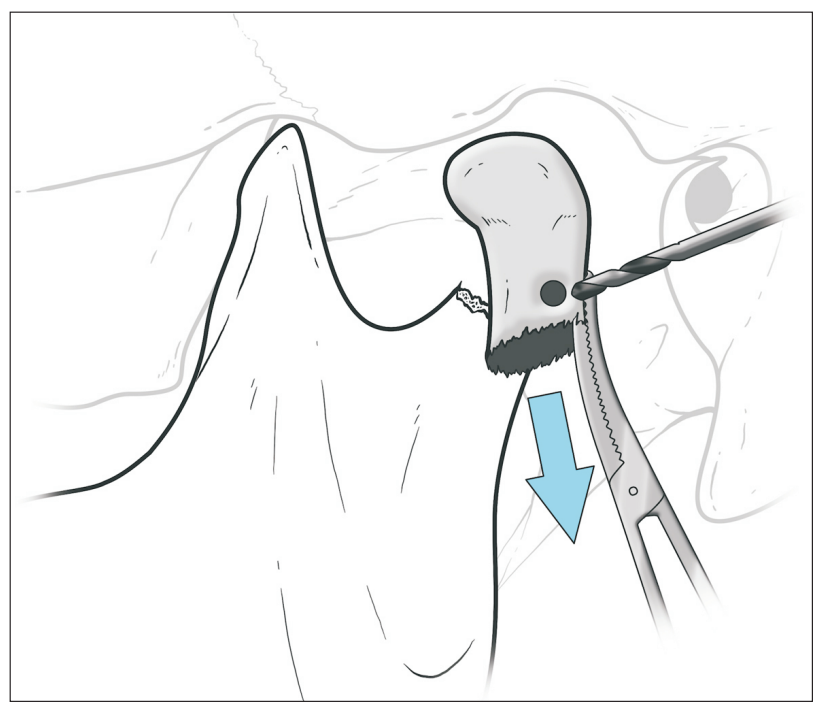

Fig. 2. Lateralization and drilling of the proximal segment for fixation of screw in hole No. 2 of the four-hole with gap titanium miniplate.

Saurabh Mohandas Kamat et al: New protocol for simplified reduction and fixation of subcondylar fractures of the mandible: a technical note. J Korean Assoc Oral Maxillofac Surg 2021 of giving stability to the proximal segment during drilling and fixation of the first screw, as well as aiding the stripping of some portion of the insertion of inferior head of the lateral pterygoid at the pterygoid fovea using the flat end of a periosteal elevator to minimize the pull exerted by the lateral pterygoid on the proximal segment.

\section{Step 3}

The antero-inferior force on the mandible is released to allow the mandible to passively distract postero-superiorly. For ease of understanding, the holes of the miniplate are numbered from 1 to 4 as illustrated in Fig. 3 .

\section{Step 4}

A hole is drilled $3 \mathrm{~mm}$ from the fracture line on the posterolateral border of the proximal segment with a $1.6 \mathrm{~mm}$ drill bit in a supero-medial direction.(Fig. 2) A $2 \mathrm{~mm}$ four-hole with gap titanium miniplate is secured to the proximal segment at hole No. 2 with a $2 \mathrm{~mm} \times 6 \mathrm{~mm}$ miniscrew. This makes the miniplate jut out laterally along the long axis of the proximal segment.(Fig. 3)

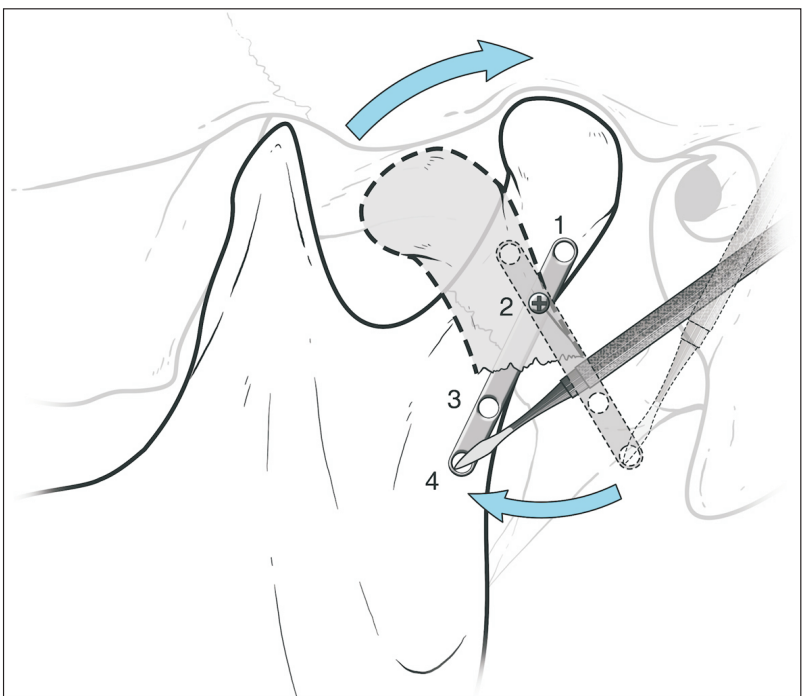

Fig. 3. Screw fixations at hole No. 2 making the miniplate jut out laterally along the long axis of the proximal segment followed by anatomical reduction of the fracture by pulling the miniplate inferiorly towards the distal segment using the sharp end of periosteal elevator in hole No. 4.

Saurabh Mohandas Kamat et al: New protocol for simplified reduction and fixation of subcondylar fractures of the mandible: a technical note. J Korean Assoc Oral Maxillofac Surg 2021 


\section{Step 5}

The mandible is antero-inferiorly distracted manually and the miniplate is pulled inferiorly towards the distal segment with the sharp end of the periosteal elevator in hole No. 4 of the miniplate.(Fig. 3)

This maneuver orients the proximal segment of the condyle in the anatomic position and realigns the posterior border with a seamless contact of the proximal and distal segments thus ensuring the restoration of condyle and glenoid fossa relationship. Caution should be exercised to avoid any bend in the miniplate due to injudicious forces that may jeopardize the final alignment outcome of the fractured segments.

\section{Step 6}

Occlusion is achieved and secured with intermaxillary fixation.

\section{Step 7}

Maintaining the downward pressure on the hole No. 4 , hole No. 3 is drilled and a $2 \mathrm{~mm} \times 8 \mathrm{~mm}$ screw is placed in the infero-medial direction helping in mild compression at the fracture line.

\section{Step 8}

Periosteal elevator from hole No. 4 is released, the same hole is drilled, and a $2 \mathrm{~mm} \times 8 \mathrm{~mm}$ screw is placed in inferomedial direction.

\section{Step 9}

The last hole No. 1 is drilled in supero-medial direction and a $2 \mathrm{~mm} \times 6 \mathrm{~mm}$ screw is placed.

\section{Step 10}

The anterior border of the proximal segment is fixed to neutralize the anterior tension zone either with a $2 \mathrm{~mm}$ 2-hole with gap or 4-hole with gap miniplate.

Standard layered closure is done using 3-0 Vicryl followed by 6-0 prolene for the skin.

\section{Discussion}

Reduction and fixation of medially displaced subcondylar fractures have always posed a challenge to a young surgeon. Peterson et al. ${ }^{5}$ described the use of a maxillo-mandibular fixation screw on the proximal segment to aid in its reduction, and also mentioned the use of temporary suture or wire around the condylar head as alternatives. However, there is no stepwise go-to guide mentioned in the literature to help surgeons in the decision making process after surgically identifying the proximal and distal segments. Open reduction and internal fixation of the subcondylar fracture helps in the restoration of ramal height, stable occlusion, and thus in early recovery to normal function ${ }^{6-10}$.

Two straight plates or three-dimensional plates are advocated for subcondylar fixation as single plate fixations have proven to cause fixation failure ${ }^{11}$. The distribution of compressive stress on the posterior border of the ramus, and tensile stress inferior and parallel to the sigmoid notch of the mandible were demonstrated by the photoelastic analysis put forth by Meyer et al. ${ }^{12}$. Two miniplates, fixed in a triangular geometry, one at the posterior ramal border and one following the curvature of the sigmoid notch, are ideal in fixation of subcondylar fractures ${ }^{13}$.

The authors employed the retromandibular transmasseteric anteroparotid approach as it is considered to be a surgeonfriendly approach ${ }^{6,14}$.

The protocol that the authors have described here does not necessitate the use of specialized instruments and its stepwise approach lends clarity and predictability to the entire procedure. The authors encountered no complications such as sialocele formation, facial nerve paralysis, infection, or postoperative restricted mouth opening in the 34 cases in which they employed this protocol. Hence, the authors believe this protocol would help all surgeons, young or experienced, to perform open reduction and internal fixation of the mandibular subcondylar region with ease and accuracy.

\section{ORCID}

Saurabh Mohandas Kamat, https://orcid.org/0000-00028580-0298

Vikas Dhupar, https://orcid.org/0000-0002-8208-1056

Francis Akkara, https://orcid.org/0000-0002-2128-6357 


\section{Authors' Contributions}

S.M.K. has conceptualized the idea of the new protocol, performed 24 cases using this protocol and prepared the manuscript (conceptualization, investigation, and writing - original draft preparation). V.D. and F.A. have performed over 32 cases amongst themselves using this protocol and contributed in validating the predictability and repeatability of this protocol with meticulous documentation (investigation, validation, and writing - review and editing).

\section{Acknowledgements}

The authors would like to thank Dr. Ashwin Mysore, Dr. Pooja Mandrekar, Dr. Mohan Naik, and Dr. Trishala Bhadauria Fernandes for their valuable inputs.

\section{Conflict of Interest}

No potential conflict of interest relevant to this article was reported.

\section{References}

1. Zide MF, Kent JN. Indications for open reduction of mandibular condyle fractures. J Oral Maxillofac Surg 1983;41:89-98. https:// doi.org/10.1016/0278-2391(83)90214-8

2. Kamel GN, De Ruiter BJ, Baghdasarian D, Mostafa E, Levin A, Davidson EH. Establishing a protocol for closed treatment of mandibular condyle fractures with dynamic elastic therapy. Plast Reconstr Surg Glob Open 2019;7:e2506. https://doi.org/10.1097/ GOX.0000000000002506

3. Loukota RA, Eckelt U, De Bont L, Rasse M. Subclassification of fractures of the condylar process of the mandible. Br J Oral Maxillofac Surg 2005;43:72-3. https://doi.org/10.1016/ j.bjoms.2004.08.018

4. Orabona GD, Abbate V, D'Amato S, Romano A, Iaconetta G. Surgical sequence of reduction in double mandibular fractures treatment. Ann Ital Chir 2014;85:207-13.
5. Peterson EC, Nguyen DC, Baughman EJ, Skolnick GB, Chi JJ, Patel KB. Algorithm for management of mandibular condylar base fractures. Plast Reconstr Surg Glob Open 2020;8:e3145. https:// doi.org/10.1097/GOX.0000000000003145

6. Bindra S, Choudhary K, Sharma P, Sheorain A, Sharma CB. Management of mandibular sub condylar and condylar fractures using retromandibular approach and assessment of associated surgical complications. J Maxillofac Oral Surg 2010;9:355-62. https://doi. org/10.1007/s12663-010-0133-5

7. Kanno T, Sukegawa S, Fujioka M, Takabatake K, Furuki Y. Transoral open reduction with rigid internal fixation for subcondylar fractures of the mandible using a small angulated screwdriver system: is endoscopic assistance necessary? J Oral Maxillofac Surg 2011;69:e372-84. https://doi.org/10.1016/j.joms.2011.02.040

8. Choi BH, Yi CK, Yoo JH. Clinical evaluation of 3 types of plate osteosynthesis for fixation of condylar neck fractures. J Oral Maxillofac Surg 2001;59:734-7; discussion 738. https://doi.org/10.1053/ joms.2001.24283

9. Rozeboom A, Dubois L, Bos R, Spijker R, de Lange J. Open treatment of unilateral mandibular condyle fractures in adults: a systematic review. Int J Oral Maxillofac Surg 2017;46:1257-66. https:// doi.org/10.1016/j.ijom.2017.06.018

10. Kim SY, Ryu JY, Cho JY, Kim HM. Outcomes of open versus closed treatment in the management of mandibular subcondylar fractures. J Korean Assoc Oral Maxillofac Surg 2014;40:297-300. https://doi.org/10.5125/jkaoms.2014.40.6.297

11. Meyer C, Serhir L, Boutemi P. Experimental evaluation of three osteosynthesis devices used for stabilizing condylar fractures of the mandible. J Craniomaxillofac Surg 2006;34:173-81. https://doi. org/10.1016/j.jcms.2005.09.005

12. Meyer C, Kahn JL, Boutemi P, Wilk A. Photoelastic analysis of bone deformation in the region of the mandibular condyle during mastication. J Craniomaxillofac Surg 2002;30:160-9. https://doi. org/10.1054/jcms.2002.0297

13. Choi BH, Kim KN, Kim HJ, Kim MK. Evaluation of condylar neck fracture plating techniques. J Craniomaxillofac Surg 1999; 27:109-12. https://doi.org/10.1016/s1010-5182(99)80023-7

14. Crowley M, Siddiqui A, Burke E. Surgical management of condylar fracture: a trainee friendly approach. Br J Oral Maxillofac Surg 2017;55:E132. https://doi.org/10.1016/j.bjoms.2017.08.136

How to cite this article: Kamat SM, Dhupar V, Akkara F. New protocol for simplified reduction and fixation of subcondylar fractures of the mandible: a technical note. J Korean Assoc Oral Maxillofac Surg 2021;47:403-406. https://doi.org/10.5125/ jkaoms.2021.47.5.403 